\title{
The foundation and consequences of gender bias in grant peer review processes
}

\author{
Rosemary Morgan PhD, Kate Hawkins MA, Jamie Lundine MSc
}

- Cite as: CMAJ 2018 April 23;190:E487-8. doi: 10.1503/cmaj.180188

See related article at www.cmaj.ca/lookup/doi/10.1503/cmaj.170901

G ender bias exists within research grant peer review processes around the world and is a manifestation of historical and systemic gender bias in academic institutions and beyond. In linked research, Tamblyn and colleagues present evidence from a cross-sectional study that shows the presence of gender bias in the grant peer review process in Canadian health research funding. ${ }^{1}$ Notably, female applicants with past grant success rates equivalent to male applicants were given lower application scores by reviewers, and male applicants with less experience than female applicants were favoured and awarded grants at a higher rate. To many women in academia, and to those who study gender inequity, these findings come as no surprise and mirror other studies that examine gender inequity within the grant peer review process internationally.

The authors of the linked study highlight how studies have shown that female research grant applicants have lower scientific productivity and are often perceived to be less competent or weaker leaders than male applicants. They explain how this can lead reviewers to view female applicants as less able to lead multiple funded projects, resulting in lower scores and funding success. These findings are important, as securing less funding slows career progression for women and reduces opportunities for publishing and other forms of collaboration, which are criteria for professional advancement. To understand why this occurs, we must recognize that gender bias within the grant review process is a manifestation of historical and systemic gender bias within academica.

Research systems in general are typically male oriented, owing to historical and systemic gender bias that has been "institutionalized as policies, practices, beliefs and written or unwritten rules of behaviour," ${ }^{2}$ as well as biases related to race, class, sexuality and other markers of difference, according to a recent global call to action. ${ }^{2}$ As a result of these systemic biases, women are universally underrepresented at higher levels of academic hierarchies, despite increasing numbers of women admitted to university. ${ }^{2}$ According to Statistics Canada, between 2016 and 2017 , only $27.6 \%$ of full professors - 4488 out of 16239 - were women. This trend of disproportionately low representation of women in academic leadership is present across academic institutions internationally.

\section{KEY POINTS}

- Gender bias within the research grant review process worldwide is a manifestation of historical and systemic gender bias within academic institutions and beyond.

- For many reasons, women are underrepresented in academic leadership; their research is less frequently cited than that of men; and they may enjoy less credit for their published work than their male coauthors.

- Efforts to overhaul processes of research grant peer review must go hand in hand with larger projects that aim to shift traditional gender norms in academia through institutional policies that recognize gender bias and act to counter it.

Several factors contribute to women's underrepresentation in the higher ranks of academia. Gender stereotypes place value on male leadership traits, which benefit men in academic appointments and promotions. ${ }^{2}$ Gender stereotypes for women may mean they are expected to undertake a larger share of household responsibilities in addition to work outside the home, ${ }^{3}$ which creates a double burden of work for women. Some academic institutions still lack policies to support both women and men who need to raise and care for their families, such as flexible working hours, adequate parental leave and child care facilities.

With fewer women in positions of leadership, female leaders are frequently asked to sit on committees and boards, ${ }^{3,4}$ including committees for documenting inequity in the academic workplace. ${ }^{5}$ According to one study, which conducted focus-group discussions with women in academia, women may feel less able to decline requests for service work (such as mentoring or sitting on committees), and that they may be penalized when they do so. ${ }^{3}$ This leaves less time for their own research, including preparing grant proposals and authoring journal articles; the situation is worse for women of colour (who also face racialized discrimination). ${ }^{6}$ Studies from across different academic disciplines have also pointed to women's underrepresentation within academic conferences and colloquia, which are important venues for both presenting emerging research and engaging in professional networking. 
Women are underrepresented as authors of research articles, ${ }^{2}$ and less frequently cited than men. ${ }^{7}$ An observational study of collaboration on journal articles, for example, found that in the field of economics, women are subject to a "coauthor penalty," which means that, while women who solo-author have roughly the same chance of receiving tenure as a man, women who coauthor most of their work have a significantly lower probability of receiving tenure. ${ }^{8}$ When women collaborate with men, they often get no credit, as it is assumed that the male author took the lead. ${ }^{8}$ In relation to citations, a large-scale observational study found that not only are men cited more than women, but men cite men more (including citing themselves). ${ }^{7}$

In addition, a growing evidence base shows that universities are sites of gendered sexual harassment, which hampers women's ability to participate fully in the workplace. ${ }^{9}$ As the academic workplace moves online, harassment and sexism are also mirrored in virtual spaces.

The findings of the linked study show a clear need to address gender bias within the grant peer review process. Fortunately, funding agencies, including the Canadian Institutes of Health Research, whose pre-reform funding process the authors studied, are beginning to put measures in place to address gender bias. ${ }^{10}$ Using a quasi-experimental study design, Witteman and colleagues documented a reduction in gender bias within the Canadian Institutes of Health Research grant-making process by instructing peer reviewers to focus on "the science" of a proposal instead of "the scientist." 11 This is an exciting new avenue of research, and other funding agencies should follow this lead.

The National Institute of Health and the European Commission both recently launched calls for research into gender and diversity in academic funding and research. The European Commission's work draws on the popularity of the United Kingdom's Equality Challenge Unit, particularly the Athena Scientific Women's Academic Network (SWAN) initiative, an award-based program that recognizes universities' recruitment, promotion and retention of women. Certain biomedical health funding is tied to Athena SWAN awards, further institutionalizing and incentivizing a push toward gender parity. ${ }^{5}$

Patriarchal structures tend to manifest in complex, multifaceted and reinforcing ways. How these processes affect women of colour, Indigenous women and academics from low-income countries is underexplored and should be a priority. Overhauling processes of peer review must go hand in hand with larger projects of transformation within academia. These should aim to shift traditional gender norms through institutional policies that recognize gender bias and act to counter it. More evidence, both quantitative and qualitative, is needed. Quantitative data allow us to understand the scale of the problem, and qualitative exploration facilitates greater understanding of the motivations, incentives and reasoning underpinning gender bias and its ramifications. Only with this recognition, and sustained collective action, will we see the long-term systemic change needed for women to have equitable chances in the grant review process and beyond.

\section{References}

1. Tamblyn R, Girard N, Qian CJ, et al. Assessment of potential bias in research grant peer review in Canada. CMAJ 2018;190:E489-99.

2. Ovseiko PV, Greenhalgh T, Adam P, et al. A global call for action to include gender in research impact assessment. Health Res Policy Syst 2016;14:50.

3. Huang PM. Breaking through glass ceilings and maternal walls in academia: focus group findings [report]. San Francisco: Center for Worklife Law; 2008. Available: http://worklifelaw.org/publications/gender-bias-academia.pdf (accessed 2018 Jan. 29).

4. Guarino CM, Borden VMH. Faculty service loads and gender: Are women taking care of the academic family? Res High Educ 2017;58:672-94. doi:10.1007/s11162 -017-9454-2.

5. Caffrey L, Wyatt D, Fudge N, et al. Gender equity programmes in academic medicine: a realist evaluation approach to Athena SWAN processes. BMJ Open 2016; 6:e012090.

6. Wijesingha R, Ramos H. Human capital or cultural taxation: What accounts for differences in tenure and promotion of racialized and female faculty? Can J High Educ 2017;47:54-75.

7. Maliniak D, Powers R, Walter BF. The gender citation gap in international relations. Int Organ 2013;67:889-922. doi:10.1017/S0020818313000209.

8. Sarsons H. Gender differences in recognition for group work [working paper]. Cambridge (MA): Harvard University; 2017. Available: https://scholar.harvard.edu/ sarsons/publications/note-gender-differences-recognition-group-work (accessed 2018 Jan. 29).

9. Jagsi R, Griffith KA, Jones R, et al. Sexual harassment and discrimination experiences of academic medical faculty. JAMA 2016;315:2120-1.

10. Tricco AC, Thomas SM, Antony J, et al. Strategies to prevent or reduce gender bias in peer review of research grants: a rapid scoping review. PLoS One 2017; 12:e0169718.

11. Witteman HO, Hendricks M, Straus S, et al. Female grant applicants are equally successful when peer reviewers assess the science, but not when they assess the scientist. bioRxiv 2017;2322868. doi:10.1101/232868.
Competing interests: Jamie Lundine reports personal fees from the Canadian Institutes of Health Research, outside the submitted work.

This article was solicited and has not been peer reviewed.

Affiliations: Department of International Health (Morgan), Johns Hopkins Bloomberg School of Public Health, Baltimore, Md.; Pamoja Communications Ltd. (Hawkins), Argyll and Bute, UK; Gender, Work and Health
Research Unit (Lundine), Telfer School of Management, University of Ottawa, Ottawa, Ont.

Contributors: All authors contributed to the conception and design of the work. Rosemary Morgan prepared the first draft of the manuscript and Kate Hawkins and Jamie Lundine revised it critically for important intellectual content. All authors gave final approval of the version to be published and agreed to be accountable for all aspects of the work.
Funding: Rosemary Morgan and Kate Hawkins are members of Research in Gender and Ethics: Building Stronger Health Systems, funded by the UK Department for International Development for the benefit of low and middle income countries [project no. P05683]. The views expressed are not necessarily those of the Department for International Development.

Correspondence to: Rosemary Morgan, rosemary.morgan@jhu.edu 